\title{
Flexible sample environment for high resolution neutron imaging at high temperatures
} in controlled atmosphere

\author{
Makowska, Malgorzata G.; Kuhn, Luise Theil; Cleemann, Lars Nilausen; Lauridsen, Erik M.; Bilheux, \\ Hassina Z.; Molaison, Jamie J.; Santodonato, Louis J.; Tremsin, Anton S.; Grosse, Mirco; Morgano, \\ Manuel \\ Total number of authors: \\ 12
}

Published in:

Review of Scientific Instruments

Link to article, DOI:

$10.1063 / 1.4937615$

Publication date:

2015

Document Version

Publisher's PDF, also known as Version of record

Link back to DTU Orbit

Citation $(A P A)$ :

Makowska, M. G., Kuhn, L. T., Cleemann, L. N., Lauridsen, E. M., Bilheux, H. Z., Molaison, J. J., Santodonato, L. J., Tremsin, A. S., Grosse, M., Morgano, M., Kabra, S., \& Strobl, M. (2015). Flexible sample environment for high resolution neutron imaging at high temperatures in controlled atmosphere. Review of Scientific Instruments, 86(12), 125109. https://doi.org/10.1063/1.4937615

\section{General rights}

Copyright and moral rights for the publications made accessible in the public portal are retained by the authors and/or other copyright owners and it is a condition of accessing publications that users recognise and abide by the legal requirements associated with these rights.

- Users may download and print one copy of any publication from the public portal for the purpose of private study or research.

- You may not further distribute the material or use it for any profit-making activity or commercial gain

- You may freely distribute the URL identifying the publication in the public portal 


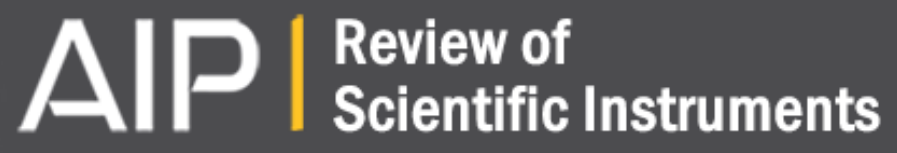

\section{Flexible sample environment for high resolution neutron imaging at high temperatures in controlled atmosphere}

Małgorzata G. Makowska, Luise Theil Kuhn, Lars N. Cleemann, Erik M. Lauridsen, Hassina Z. Bilheux, Jamie J. Molaison, Louis J. Santodonato, Anton S. Tremsin, Mirco Grosse, Manuel Morgano, Saurabh Kabra , and Markus Strobl

Citation: Review of Scientific Instruments 86, 125109 (2015); doi: 10.1063/1.4937615

View online: http://dx.doi.org/10.1063/1.4937615

View Table of Contents: http://scitation.aip.org/content/aip/journal/rsi/86/12?ver=pdfcov

Published by the AIP Publishing

\section{Articles you may be interested in}

A new apparatus design for high temperature (up to $950^{\circ} \mathrm{C}$ ) quasi-elastic neutron scattering in a controlled gaseous environment

Rev. Sci. Instrum. 86, 095102 (2015); 10.1063/1.4929580

Revealing microstructural inhomogeneities with dark-field neutron imaging

J. Appl. Phys. 107, 036101 (2010); 10.1063/1.3298440

High-temperature furnace for dynamic neutron radiography

Rev. Sci. Instrum. 74, 3717 (2003); 10.1063/1.1592878

Imaging of neutron incoherent scattering from hydrogen in metals

J. Appl. Phys. 91, 3669 (2002); 10.1063/1.1452769

Contrast mechanisms for neutron radiography

Appl. Phys. Lett. 78, 1011 (2001); 10.1063/1.1347387

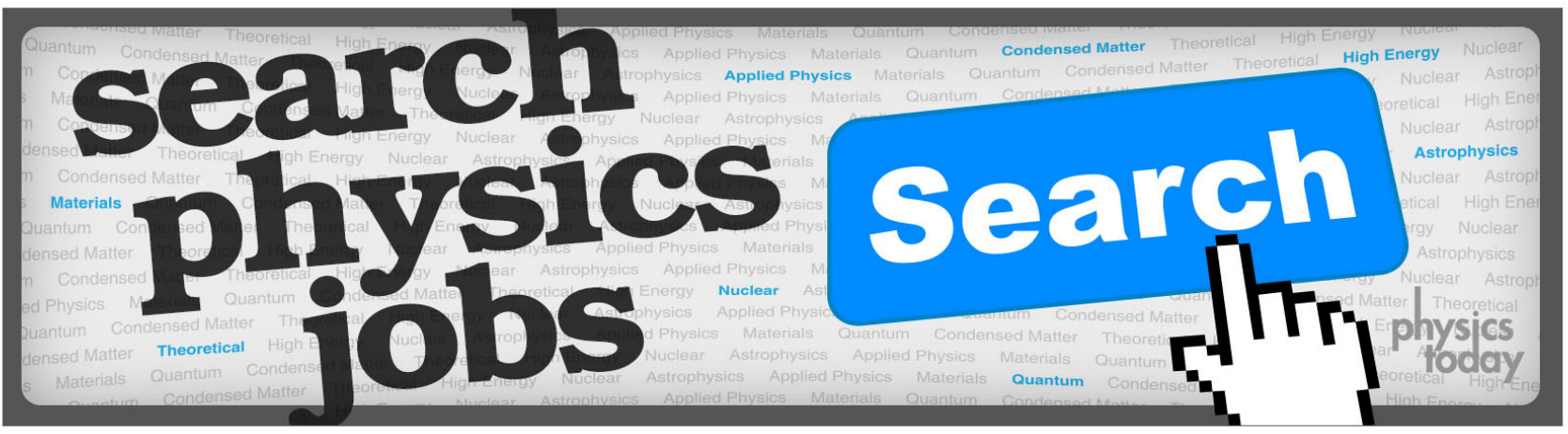




\title{
Flexible sample environment for high resolution neutron imaging at high temperatures in controlled atmosphere
}

\author{
Małgorzata G. Makowska, ${ }^{1,2, a)}$ Luise Theil Kuhn, ${ }^{1}$ Lars N. Cleemann, ${ }^{1}$ Erik M. Lauridsen, ${ }^{3}$ \\ Hassina Z. Bilheux, ${ }^{4}$ Jamie J. Molaison, ${ }^{4}$ Louis J. Santodonato, ${ }^{4}$ Anton S. Tremsin, ${ }^{5}$ \\ Mirco Grosse, ${ }^{6}$ Manuel Morgano, ${ }^{7}$ Saurabh Kabra, ${ }^{8}$ and Markus Strobl ${ }^{2}$ \\ ${ }^{1}$ Department of Energy Conversion and Storage, Technical University of Denmark, Roskilde 4000, Denmark \\ ${ }^{2}$ European Spallation Source ESS AB, P.O. Box 176, SE-221 00 Lund, Sweden \\ ${ }^{3}$ Xnovo Technology ApS, Galoche Alle 15, Koge 4600, Denmark \\ ${ }^{4}$ Oak Ridge National Laboratory, Oak Ridge, Tennessee 37831, USA \\ ${ }^{5}$ Space Sciences Laboratory, University of California at Berkeley, Berkeley, California 94720, USA \\ ${ }^{6}$ Institute for Applied Material Research, Karlsruhe Institute of Technology, Karlsruhe DE-76021, Germany \\ ${ }^{7}$ Paul Scherrer Institut, Villigen PSI CH-5232, Switzerland \\ ${ }^{8}$ ISIS, Rutherford Appleton Laboratory, Chilton OX11 0QX, United Kingdom
}

(Received 25 September 2015; accepted 28 November 2015; published online 17 December 2015)

\begin{abstract}
High material penetration by neutrons allows for experiments using sophisticated sample environments providing complex conditions. Thus, neutron imaging holds potential for performing in situ nondestructive measurements on large samples or even full technological systems, which are not possible with any other technique. This paper presents a new sample environment for in situ high resolution neutron imaging experiments at temperatures from room temperature up to $1100^{\circ} \mathrm{C}$ and/or using controllable flow of reactive atmospheres. The design also offers the possibility to directly combine imaging with diffraction measurements. Design, special features, and specification of the furnace are described. In addition, examples of experiments successfully performed at various neutron facilities with the furnace, as well as examples of possible applications are presented. This covers a broad field of research from fundamental to technological investigations of various types of materials and components. () 2015 AIP Publishing LLC. [http://dx.doi.org/10.1063/1.4937615]
\end{abstract}

\section{INTRODUCTION}

Due to high penetration power of neutrons for many engineering materials such as metals and ceramics, neutron imaging has proven to be a strong tool for studies of macroscopic samples, but also for experiments requiring significant amounts of additional materials (e.g., sample holders, containers) or even devices in the direct beam. Thus, this technique holds great potential for the use of sophisticated sample environments while still remaining sensitive to the contained sample and thereby enabling in situ studies of operating engineering devices. Highly specialized sample environments have long been developed for a wide range of neutron experiments. Many of such environments are custom designed for specific neutron techniques, requiring different beam access and exit windows covering certain angular ranges and implying severe limitations to designs and achievable performance. ${ }^{1}$ Neutron imaging ${ }^{2,3}$ in the general case only requires measurement of the transmitted beam, but has very specific requirements regarding the proximity of the sample to the detector while still maintaining the option of sample rotation for tomography. Also the beam size in most cases is significantly larger than for most, if not for all other neutron techniques, i.e., the field of view should not be limited by the sample environment.

In recent years the spatial image resolution with neutrons, crucial for many applications of this technique,

a)Electronic mail: malg@dtu.dk has been improved significantly and recent approaches aim at below $10 \mu \mathrm{m}$ through significant improvements in detection technology. ${ }^{4,5}$ The achievable spatial resolution depends on the imaging instrument setup (collimation of the beam) and the detector. Beam collimation is especially important, when the sample is placed at some distance from the detector. Increasing this distance tremendously decreases the achievable spatial resolution due to the neutron beam divergence. On the other side, additional beam collimation decreases the available flux, again hindering resolution, in particular, time resolution, which is crucial for in situ experiments. Hence, a compromise between neutron beam intensity and spatial resolution must be made by choosing the collimation ratio $\mathrm{L} / \mathrm{D}$, where $\mathrm{L}$ is the aperture-sample distance, and D is the aperture size. The geometric resolution limit is then given by the blur $\mathrm{b}=\mathrm{d} /(\mathrm{L} / \mathrm{D})$, where $\mathrm{d}$ is the sample-to-detector distance. In experiments requiring a sample environment, this distance is therefore a critical part of the design.

Neutron imaging is a measurement technique, which provides insights into both macroscopic and microscopic features of the studied objects. ${ }^{2,3}$ Attenuation contrast neutron radiography and tomography allow observations of inner structures of bulk objects, e.g., differences in density, cracks, pores, water, and hydrogen concentrations and uptake. ${ }^{6-8}$ By means of advanced techniques, e.g., energy resolved neutron imaging, ${ }^{9-12}$ it is possible to gain spatially resolved information about the presence of different structural phases, texture related features or strains. ${ }^{13-17}$ As a nondestructive technique, it holds great potential 
for corresponding observations of the kinetics of many important processes including phase transitions and changes in microstructure and crystal structure or stress fields in materials under variable conditions. However, establishing in situ investigations of such processes in a neutron beam often requires specific sample environments like cryostats, ${ }^{18}$ magnets, ${ }^{19}$ or furnaces, ${ }^{1,20}$ which add limitations to the acquisition of high quality data.

In the last decade, great interest and rapid development of solid oxide electrochemical cells (SOCs) — both solid fuel cells and electrolysis cells (SOFCs and SOECs, respectively) (Refs. 21-23) for efficient and sustainable energy conversion-has shown a need for in situ observation of processes taking place during the operation of the cells. SOFCs are very promising devices for direct conversion of chemical energy into electric energy, but the technology still requires a lot of effort in optimization of their performance, lifetime and mechanical stability. Neutron imaging holds the potential of providing crucial in situ information about degradation processes taking place in the SOFCs, which presently cannot be achieved using any other experimental technique. Due to the required high operation temperature (about $800{ }^{\circ} \mathrm{C}$ ) and reactive gases, in situ experiments must be performed in an environment providing the required conditions for SOFC operation.

Furnaces commonly used for SOFC electrical characterization are not suitable for neutron imaging experiments, among others, because of thick insulation made of strongly scattering or attenuating materials and several hours long heating and cooling times. Standard furnaces presently available at neutron facilities are not suitable for SOFC measurements, as they usually operate under vacuum or inert gas atmosphere. Furthermore, they are not well suited for high resolution imaging due to inherently large sample-detector distances,,${ }^{1,20}$ and feature slow heating and cooling rates as well (a few hours). The possibility of very fast change of operating conditions (especially temperature) in a sample environment would, besides saving valuable beamtime, be of great advantage in particular for better control of the investigated processes, i.e., it would enable in situ changing of reaction rates or starting and interrupting studied processes. The need for in situ SOFC characterization by neutron imaging was the motivation for the design of a new sample environment, which we present in this work. For the study of hydrogen uptake by nuclear fuel cladding materials during oxidation in steam as well as to investigate the hydrogen diffusion in zirconium a special furnace called INRRO (In situ Neutron Radiography Reaction Oven) was constructed at KIT. ${ }^{24,25}$ The furnace can operate at temperatures up to $1500^{\circ} \mathrm{C}$. The spatial resolution of experiments with this furnace is relatively low because of the large sample detector distance of about $200 \mathrm{~mm}$.

Besides the initially planned application, the presented furnace has great potential for various other studies such as, e.g., SOEC characterization and degradation; high resolution hydrogen uptake in metals (e.g., nuclear fuel claddings ${ }^{7,8}$ ); crystal annealing, melting, recrystallization; and gas conversion and transport in catalysts and membranes. $^{26,27}$

\section{FURNACE DESIGN}

Here we present a specialized furnace designed for high resolution kinetics in situ neutron imaging measurements of processes requiring high temperatures of up to $1100^{\circ} \mathrm{C}$ and/or controlled atmospheres of reactive gasses with flow rates up to $150 \mathrm{l} / \mathrm{h}$. The design of the furnace was chosen so as to avoid the experimental issues described above and to achieve high flexibility, meaning the capability to accommodate a very broad field of applications from small samples to large devices as well as easy and fast mounting at any neutron imaging instrument.

\section{A. Heating method}

The most important feature of the furnace is the applied heating system, as it determines all related parameters like maximum temperature, heating/cooling rates, the design of the chamber including sample-detector distance, and the covered sample size range and positions.

Heating of the sample is based on absorption of electromagnetic radiation emitted from two (with the option of four) infrared heaters purchased from PRECISION CONTROL SYSTEMS, INC. ${ }^{28}$ Each heater is equipped with six halogen quartz lamps and water-cooled polished aluminum reflectors (Figure 1), which provides a $100 \mathrm{~mm} \times 75 \mathrm{~mm}$ heating area (non-focused radiation) and consumes $6 \mathrm{~kW}$ electric power. This method of heating of samples is very convenient for neutron experiments, as it allows reaching the required stable temperature in less than a few minutes depending on the sample mass and composition. The efficient control of the heaters allows very efficient use of neutron beamtime and quick changes of experimental conditions. Control of the heaters is performed using a customized program written in LabVIEWTM, which is described in the Section II G. The radiation heating method combined with the design of the furnace, where only the sample (and not the environment) is directly heated, allows for very fast sample cooling, since only the sample (and not the environment) is heated. The actual cooling rate depends on

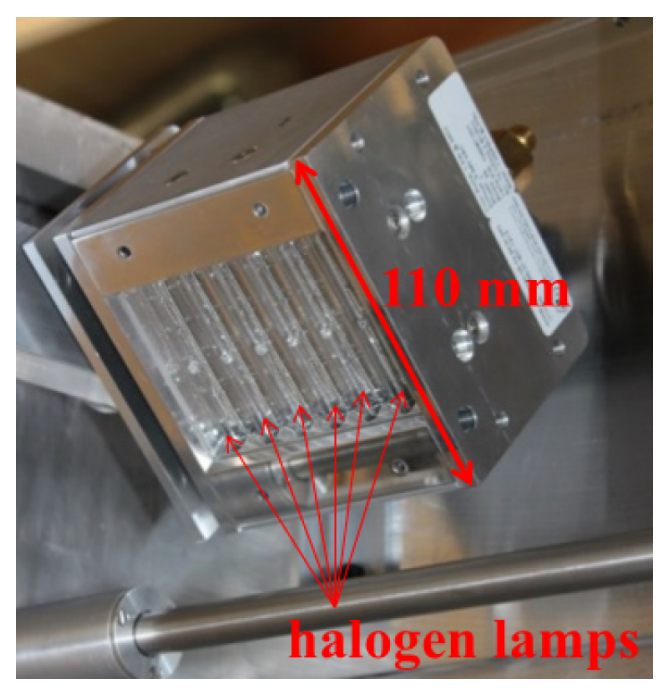

FIG. 1. Infrared heater with six halogen quartz lamps placed in the furnace. 
sample composition, mass and volume. In the case of the experiment on SOC electrodes described in this paper, where relatively small ceramic-metal composite specimens of a few $\mathrm{mm}^{3}$ were studied, the cooling process was so efficient that it was possible to exchange samples after a few minutes. This corresponds to the time required for stopping the neutron measurement and subsequent procedures (e.g., beam shutter closing and opening the radiation shielded hutch of the neutron instrument), without additional waiting time for the furnace to cool down. The high heating and cooling rates together with precise control of those broadens the field of applications of the furnace e.g., if the observed processes must be stopped at a certain time or the sample must be quickly cooled or heated.

\section{B. Chamber design}

The employed heating method by radiation absorption allows the use of a lightweight furnace chamber, since no insulation is needed.

The chamber dimensions are $400 \times 600 \times 600 \mathrm{~mm}^{3}$ (Figure 2) and it is composed of a frame and dismountable top, side and back walls and a water-cooled back panel with a thin aluminum window, through which neutrons pass before reaching the detector (later called "neutron window"). Large dimensions give the possibility of investigating relatively large samples with the additional option to add heaters and position them with great flexibility within the chamber.

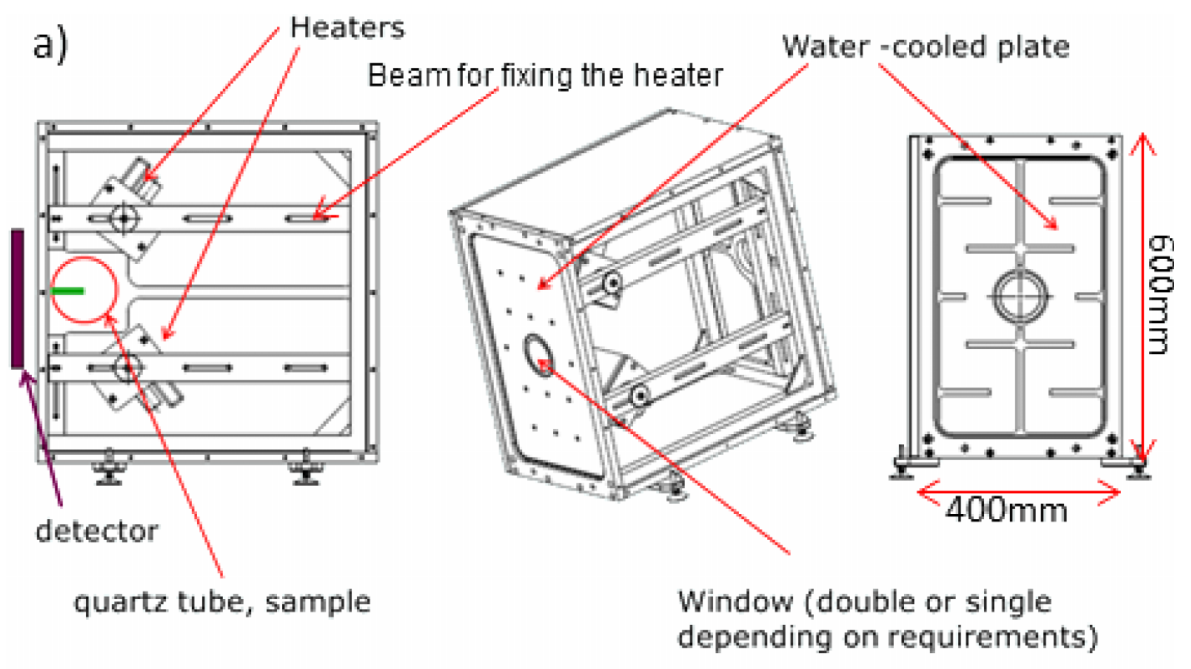

b)

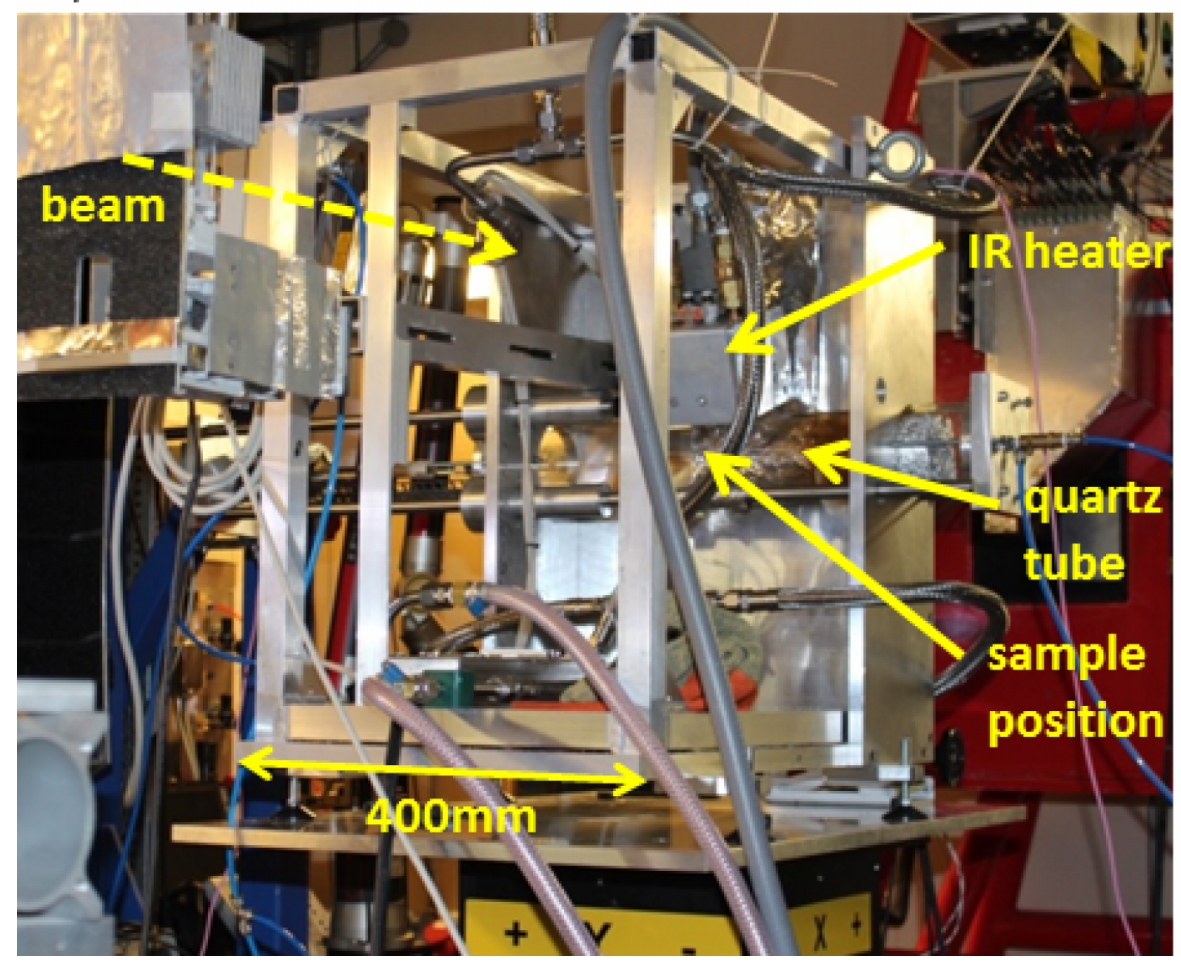

FIG. 2. (a) Furnace drawings presenting design of the chamber with possible positions of a sample, a detector and the heaters (they can be moved along the horizontal beam, and the beam can be moved up and down). (b) Picture of the open furnace chamber set for experiments at the ENGIN-X instrument at ISIS (UK) also indicating the neutron beam direction through the furnace. 
TABLE I. Compositions of alloys used for the furnace chamber. This ensures low risk of activation during neutron exposure.

\begin{tabular}{lcccccccrr}
\hline \hline Furnace element/alloy & $\mathrm{Si}(\%)$ & $\mathrm{Fe}(\%)$ & $\mathrm{Cu}(\%)$ & $\mathrm{Mn}(\%)$ & $\mathrm{Mg}(\%)$ & $\mathrm{Cr}(\%)$ & $\mathrm{Zn}(\%)$ & $\mathrm{Others}(\%)$ & $\mathrm{Al}$ \\
\hline $\begin{array}{l}\text { Frame, walls EN } \\
\begin{array}{l}\text { AW-6060/63 } \\
\text { Window EN AW-6082 }\end{array}\end{array}$ & $0.20-0.60$ & 0.35 & 0.10 & 0.10 & $0.45-0.90$ & 0.10 & 0.10 & 0.30 & $\mathrm{Rest}$ \\
\hline \hline
\end{tabular}

Cooling of the back panel is necessary to avoid exposing the neutron detector to high temperatures. This will be described in more detail in Section II D. The chamber elements are made of lightweight aluminum alloys produced by Alumeco A/S. ${ }^{29}$ This composition was chosen to minimize neutron activation (very short radioactive decay half-life and small neutron cross-section of $\mathrm{Al}$ make it an advantageous material for neutron measurements) and is given in Table I. The weight of the chamber in its basic version, i.e., without removable top and walls is $35 \mathrm{~kg}$. All heavy elements e.g., heaters can easily be mounted once the chamber is in position for the neutron radiography measurements. Therefore, despite relatively large dimensions, the furnace can be mounted within an hour at a neutron beamline without the need of a crane. The chamber has four adjustable feet for horizontal alignment.

A quartz tube can be mounted around the sample position when a controlled atmosphere is required (see Section II D).

The possibility of having an open chamber increases significantly the cooling rate of the samples.

In the center of the water-cooled back panel there is a neutron window of $70 \mathrm{~mm}$ diameter (Figure 2) made of $1 \mathrm{~mm}$ thin sheet of a high strength aluminum alloy (EN AW-6082). The composition of the alloy used for the window can be found in Table I. The details of the back panel are described in Section II D.

After a 4-days constant exposure to a high flux neutron beam $\left(1.7 \times 10^{8} \mathrm{n} \mathrm{cm}^{-2} \mathrm{~s}^{-1}\right.$ BOA beamline at the Paul Scherrer Institut $\left.(\mathrm{PSI})^{30}\right)$, the radiation level of the furnace was below $5 \mu \mathrm{Sv} / \mathrm{h}$.

\section{Sample position}

As it was explained before, the optimum sample position for high resolution imaging is just in front of the neutron window in close proximity of the detector. For SOC applications, as presented later in this publication, the sample is inside a quartz tube placed parallel and at close proximity to the neutron window. The tube is utilized for experiments in a controlled atmosphere. The tube is sealed at the ends and it is equipped with gas inlet and outlet on opposite ends. The gas flow can be controlled by the same program as for the temperature control (detailed description in Section II E). The boron-free quartz tube, purchased from Windsløv Glas, is $90 \mathrm{~mm}$ in outer diameter and has $2 \mathrm{~mm}$ wall thickness. The neutron window and quartz tube walls are the only elements of the furnace, through which the neutron beam has to pass to reach the sample and detector, therefore only a negligible part of flux is lost. This flux loss was measured to be within a few percent, depending on the neutron energy spectrum.

The distance between the window (inner surface) and the quartz tube is $2 \mathrm{~mm}$, and the sample holder is placed very close $(\mathrm{mm})$ to the inner surface of the quartz tube for our measurements. Consequently, the sample-detector distance (assuming that the detector is touching the $20 \mathrm{~mm}$ thick back wall of the furnace) can be as small as $25 \mathrm{~mm}$. This is an essential feature, which makes this furnace design unique. To the best of our knowledge this is the first published furnace having this advantage, which makes it the first furnace dedicated for high resolution in situ neutron imaging measurements.

\section{Detector protection}

High temperatures are harmful for any neutron imaging detector, therefore safe operation only a few tens of millimeters away from a hot sample requires very efficient temperature control and cooling with respect to the exterior surface at the window, where the detector is placed. In this furnace this challenge has been solved by water cooling of the back panel placed between the detector and the sample holder. Water is flowing constantly through channels inside the panel, and omits only the window area. The temperature of cooling water should be in the range of $15^{\circ} \mathrm{C}-25^{\circ} \mathrm{C}$, and the required flow is $180-300 \mathrm{l} / \mathrm{h}$. The window, made from aluminum alloy, is cooled efficiently by the surrounding material due to excellent heat conduction properties. Inside the furnace, the aluminum walls act as reflectors, so heating of the window due to absorption is much less efficient than heating of the sample and sample holder. However, after a long measurement time (more than an hour), the temperature of all of the surroundings of the sample is elevated (ranging from room temperature to sample temperature, depending on the distance from the sample) due to convection and heat conduction. However, the water cooling system is sufficient to keep the temperature outside the neutron window facing the detector stable and close to room temperature $\left(<40^{\circ} \mathrm{C}\right)$, even after very long experiments (more than $10 \mathrm{~h}$ ), which is monitored by a thermocouple. Examples of temperatures measured in front of the detector during time-consuming experiments are illustrated in Table II. The negligible heating of the window shows that the applied cooling system assures safe operation

TABLE II. Temperatures measured outside the furnace (at detector position) during long term running (up to $10 \mathrm{~h}$ ). Presented values were stable.

\begin{tabular}{lc}
\hline $\begin{array}{l}\text { Sample temperature } \\
(\text { sample-detector distance } 30 \mathrm{~mm})\end{array}$ & $\begin{array}{l}\text { Temperature in front of detector } \\
\left(\text { room temperature equal } 23{ }^{\circ} \mathrm{C}\right) \\
\left({ }^{\circ} \mathrm{C}\right)\end{array}$ \\
\hline 600 & 28 \\
700 & 31 \\
1000 & 36 \\
\hline
\end{tabular}




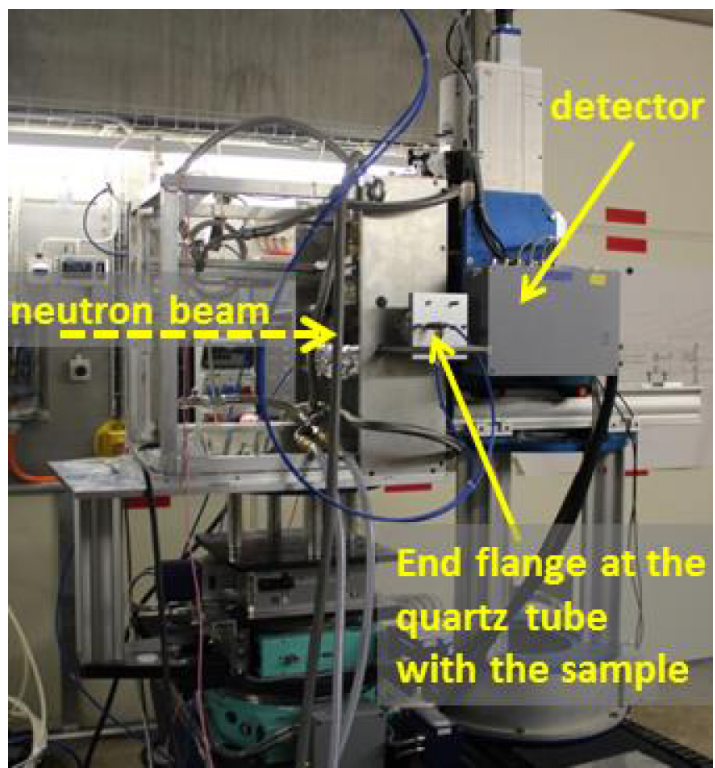

FIG. 3. Furnace mounted directly in front of a neutron imaging detector at the BOA beamline (PSI)-CCD camera with a scintillator.

of neutron imaging detectors. Figure 3 presents a photo of the furnace installed at the BOA beamline (PSI, Switzerland) with the detector (CCD camera with a scintillator) $)^{4,30}$ mounted in direct contact with the furnace back panel.

\section{E. Sample holder}

The sample holder is an element, which can be designed for specific applications and can easily be exchanged. The currently used sample holder was especially designed for mechanical SOFC anode support ${ }^{31}$ studies. Details and requirements of this experiment are described in Section III A.

The sample holder used for this described experiment was manufactured from the oxidation and corrosion resistant material Inconel@, and its design is presented in Figure 4. It is composed of a long arm, on one side connected with a precise stepper motor (min. step $0.01^{\circ}$, SMC Corporation, model LER10) used for alignment of the sample or for tomography. On the one end of the holder the sample is fixed, and on the other edge of the sample a load (different load sizes are available) can be fixed to the sample (for experiments requiring external load). The sample temperature is controlled by a thermocouple, which is placed in touch with the bottom of the sample in the non-irradiated (by heater) area.

\section{F. Specifications}

Heating and cooling rates depend on furnace settings, e.g., number of heaters and their position, as well as sample position, size and material. Therefore the furnace settings can be optimized for a given application. Table III presents parameters obtained with settings applied for measurements of SOFC anode supports mentioned above.

A crucial parameter in neutron imaging is spatial resolution. Figure 5 illustrates the effect of the furnace on the achievable spatial resolution, which is related mainly to sample position. Neutron radiographs of the PSI Siemens $\operatorname{star}^{32}$ placed at $\mathrm{d}=3 \mathrm{~mm}$ from the detector (Fig. 5(a)) and at the sample position in the furnace (here $\mathrm{d}=35 \mathrm{~mm}$ from detector) with L/D ratio equal to 485 (Fig. 5(b)) and 285 (Fig. 5(c)) were acquired at the SNAP instrument ${ }^{33}$ at the Spallation Neutron Source (SNS) at the Oak Ridge National Laboratory (ORNL) using a micro-channel-plate (MCP) detector. ${ }^{34,13}$ These images indicate spatial resolutions of about $150 \mu \mathrm{m}, 170 \mu \mathrm{m}$, and $200 \mu \mathrm{m}$, respectively, which prove that the spatial resolution, which can be achieved with the furnace in place, is very close to the intrinsic spatial resolution of the detector system, which is theoretically $110 \mu \mathrm{m}$ when operating in time-of-flight (TOF) mode.

\section{G. Furnace control}

The furnace, in particular temperature, gas valves, gas flow, and sample rotation is controlled remotely from PC. The control program was written in LabVIEW environment. The program communicates with the analog power controller of the heaters via a Eurotherm $₫ 3216$ controller. For gas flow, a mass flow controller MFC (MKS Instruments, Inc.) is used. The LabVIEW user interface enables the programming of entire measurement cycles composed of steps with different gas flows and at different temperatures.

The angular position of the sample (rotation/alignment) is controlled remotely using a software provided by the producer of the stepper motor (SMC Corporation) together with an actuator and a controller independent of the furnace controls.

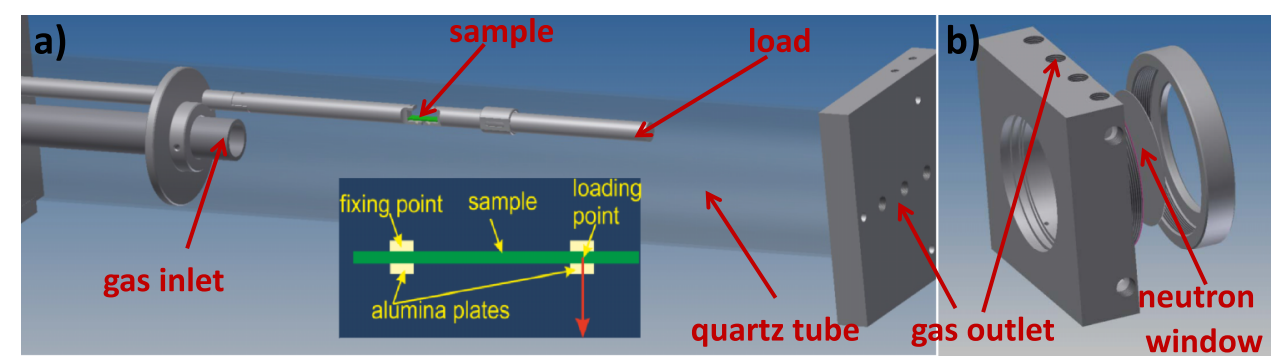

FIG. 4. (a) Quartz tube with the Inconel sample holder and a solid end flange for direct imaging measurements. The inset illustrates the load applied on the sample. (b) End flange with neutron window and gas outlets on the side for diffraction measurements. 
TABLE III. Example of parameters achieved with the furnace with settings optimized for SOFC anode support reduction studies (example of application described later). Parameters can be different for other sample size and material.

\begin{tabular}{|c|c|c|}
\hline Parameter & Range/value & Comments \\
\hline Temperature & $\begin{array}{l}\text { Room temperature }-1100^{\circ} \mathrm{C} \\
\text { (tested range) }\end{array}$ & $\begin{array}{l}\text { The highest achievable temperature } \\
\text { (which depends on sample and } \\
\text { settings) is expected to be } 1400{ }^{\circ} \mathrm{C}\end{array}$ \\
\hline $\begin{array}{l}\text { Atmosphere } \\
\text { (possibility of use of } 3 \\
\text { different gases at once) }\end{array}$ & $\begin{array}{l}\text { Any inert gas (e.g., nitrogen, } \\
\text { argon), air, oxygen, gas } \\
\text { mixtures (e.g., } 1 \%-9 \% \mathrm{H}_{2}+\mathrm{N}_{2} \text { ) }\end{array}$ & $\begin{array}{l}\text { The setup can be adapted for more } \\
\text { gases }\end{array}$ \\
\hline Pressure & Atmospheric & $\begin{array}{l}\text { The setup is designed for atmospheric } \\
\text { pressure, therefore for safety reasons it } \\
\text { is equipped with a pressure release } \\
\text { valve }\end{array}$ \\
\hline Gas flow & $0-120 \mathrm{l} / \mathrm{h}$ & Limit of the mass flow controller \\
\hline Maximal heating rate & $1 \min \left(700^{\circ} \mathrm{C}\right)$ & These values were achieved with one \\
\hline (time needed to reach & $2 \min \left(800^{\circ} \mathrm{C}\right)$ & heater, and applying the second heater \\
\hline required temperature) & $5 \min \left(1000^{\circ} \mathrm{C}\right)$ & will increase heating rate significantly. \\
\hline Temperature stability & $\begin{array}{l} \pm 1^{\circ} \mathrm{C} \text { immediately after } \\
\text { reaching setpoint } \\
\pm 0.1^{\circ} \mathrm{C} \text { after } 10 \text { min at setpoint }\end{array}$ & \\
\hline Cooling rate & $\begin{array}{l}300^{\circ} \mathrm{C} \text { in } 2 \text { min after switching } \\
\text { of the heater (cooling from } \\
800^{\circ} \mathrm{C} \text { ) }\end{array}$ & $\begin{array}{l}\text { This value was achieved in the quartz } \\
\text { tube with gas flow, which enhances } \\
\text { cooling }\end{array}$ \\
\hline Sample size & $\begin{array}{l}90 \mathrm{~mm} \text { diameter tube } \\
\text { determines the actual sample } \\
\text { size }\end{array}$ & $\begin{array}{l}\text { After minimal setup modifications } \\
\text { samples can be larger (up to } \\
150 \times 150 \mathrm{~mm}^{2} \text { ), however the field of } \\
\text { view is limited to the window size } \\
\text { ( } 70 \mathrm{~mm} \text { diameter) }\end{array}$ \\
\hline
\end{tabular}

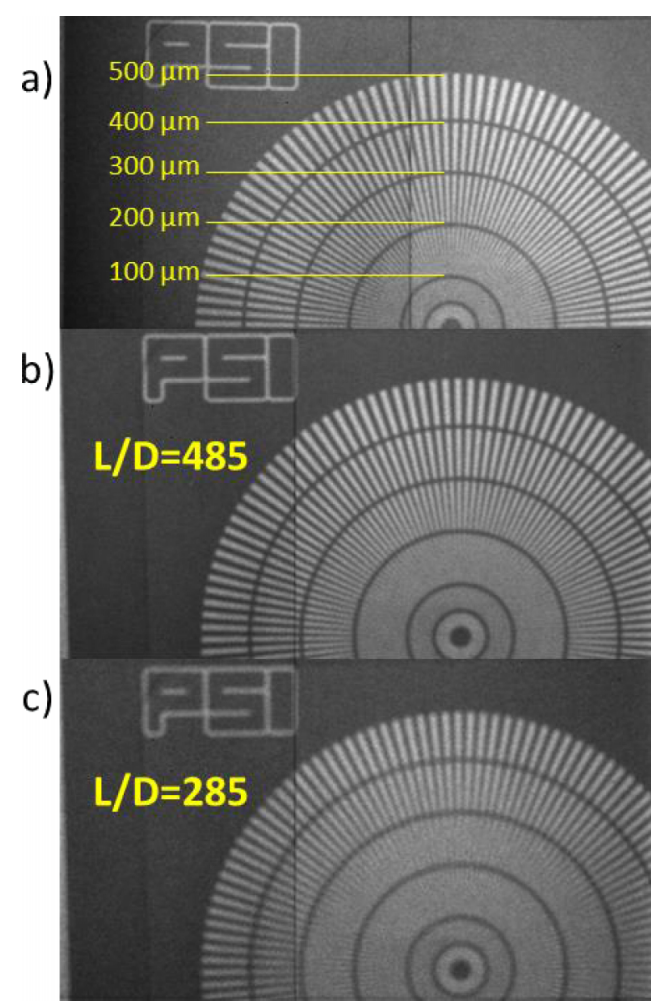

FIG. 5. Neutron radiographs of PSI Siemens star placed (a) $3 \mathrm{~mm}$ from the detector, (b) at sample position (35 $\mathrm{mm}$ from the detector) for collimation ratio equal to 485 and (c) at sample position for collimation ratio equal to 285.

\section{APPLICATIONS}

\section{A. Examples of experiments conducted with the furnace}

The furnace can be used for in situ neutron imaging measurements of processes requiring high temperature and controlled atmospheres. Here we present several examples of high resolution measurements performed with this furnace.

\section{SOC electrodes characterization}

Energy resolved neutron imaging was used to observe a critical phase transition in anode supports for SOCs. The goal of the experiment was to investigate the effect of applied stress on the reduction progress in SOFC anode supports. The samples were made with state of the art material for anode supports: $\mathrm{NiO}-\mathrm{YSZ}$ (yttria $\left(\mathrm{Y}_{2} \mathrm{O}_{3}\right)$ stabilized zirconia $\left(\mathrm{ZrO}_{2}\right)$ ) composite. Sample preparation for in situ experiments in the furnace is described in Ref. 35. The samples were solid state layers of dimensions $1 \times 7 \times 20 \mathrm{~mm}^{3}$ ( $7 \mathrm{~mm}$ parallel to the neutron beam). By means of energy resolved neutron imaging changes in $\mathrm{NiO}$ and $\mathrm{Ni}$ phase distributions and corresponding deformations due to applied stress during the reduction process were investigated. The reaction was conducted at temperatures varying from $600{ }^{\circ} \mathrm{C}$ to $850{ }^{\circ} \mathrm{C}$ with a flow of $100 \mathrm{l} / \mathrm{h}$ of $9 \% \mathrm{H}_{2}+91 \% \mathrm{~N}_{2}$. 
More detailed description of SOC composition and production can be found in Ref. 31. During the assembly of the SOC stacks and during the operation, the cells are exposed to external stresses. At the initial step of operation and later during red-ox cycling phase transitions between nickel oxide and nickel take place. The first reduction reaction determines the microstructure and later cycles change it significantly. Therefore these processes are critical for the performance and lifetime of the entire fuel (or electrolysis) cell.

The results of experiments conducted at the pulsed neutron source ISIS (UK) at the ENGIN-X beamline, are presented in Figure 6(a). The reduction reaction was conducted in the time steps ranging from 1 to $20 \mathrm{~min}$ of reduction at $650{ }^{\circ} \mathrm{C}$ in an atmosphere of $9 \% \mathrm{H}_{2}$ in $91 \% \mathrm{~N}_{2}$. Before and after each reduction reaction step neutron imaging was conducted with acquisition times of $30 \mathrm{~min}$ in order to obtain good statistics. The presented plots show Bragg edge patterns averaged over a whole sample, but it is possible to extract such patterns for smaller areas of the sample, even for single pixels with longer exposure times. The positions of the edges in the patterns correspond to lattice spacings of the crystalline structures present in the measured sample, and the height of edges depends on the amount of the corresponding phase. Thus, this measurement provides quantitative spatially resolved information about changes in phase content in the sample with respect to applied stress and reduction. The quantification procedure of such measurements is described in Ref. 36.
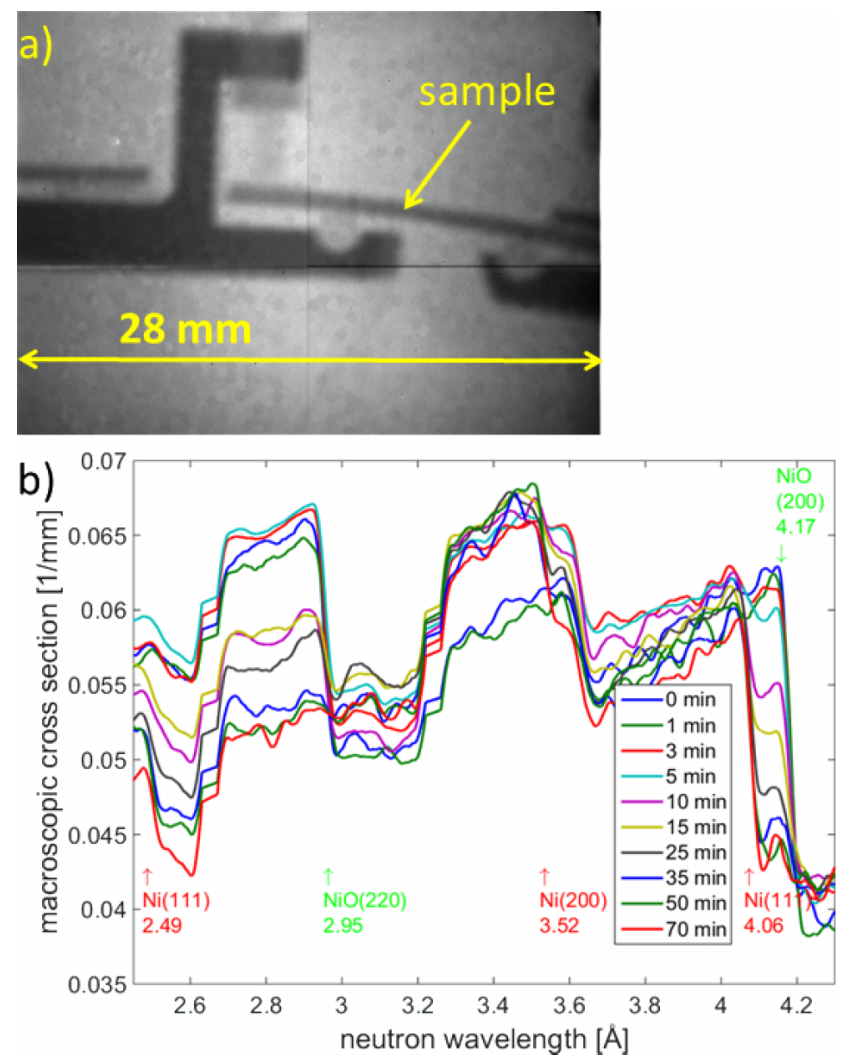

FIG. 6. (a) Neutron radiograph of the sample; (b) Bragg edge patterns for SOFC anode supports samples after different times of reduction (ENGIN-X, ISIS (UK)). a)

$\mathrm{Ni}$

b)

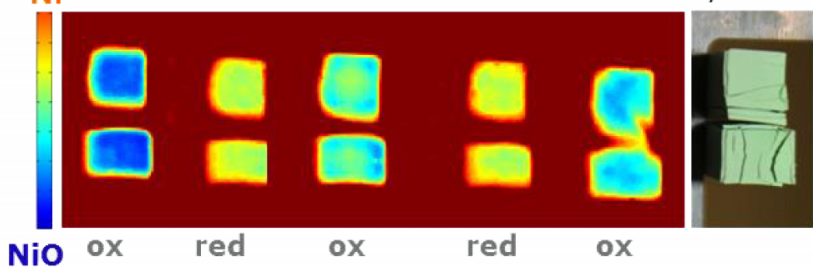

FIG. 7. (a) Example of in situ neutron imaging of phase transition during red-ox cycling of material for anodes for SOFC at $850{ }^{\circ} \mathrm{C}$ measured at BOA beamline (PSI), (b) picture of samples after experiment.

The ultimate purpose of the furnace is in situ measurements, and examples of such experiments are presented in detail in Ref. 37. Nevertheless experiments performed in steps (when neutron imaging is performed after each reaction step) give complementary information, as they enable long exposure times and hence improved statistics as compared to the real in situ series. This kind of experiment demonstrates well the flexibility of the furnace: obtaining data with high spatial resolution and by "freezing" of the investigated process at a certain stage, by quick changes of temperature and atmosphere. The spatial resolution of the images taken during this experiment was about $200 \mu \mathrm{m}$.

Figure 7 presents the results of an experiment conducted at the continuous neutron source SINQ (PSI, Switzerland) at the BOA beamline. In this case, energy selective neutron imaging was applied for the first time for the simultaneous observation of the phase transition and crack formation after several red-ox cycles of the SOFC anode material. This measurement has been performed using monochromatic neutron beam with wavelength corresponding to Bragg edge characteristic for $\mathrm{NiO}(2.95 \AA)$. The color scale in Figure 7(a) indicates the percentage of reduced phase ( $\mathrm{Ni}$, orange) and non-reduced phase ( $\mathrm{NiO}$, blue) in the samples after consecutive reduction and oxidation processes. Image analysis of this experiment is complex, because of the cracks appearing in the material during the process. Presence of the cracks in the samples increases the neutron transmission. Size and density of the cracks in this case does not however introduce significant error in phase amount evaluation. In principle, in radiography images only the biggest cracks can be spotted (visible at the Fig. 7(a)) as both an increase in transmission and change of the sample shape. Big cracks can also locally affect the evaluation of phase distribution. In order to better distinguish the signal coming from cracks and from phase distribution, additional post measurement imaging or tomography with white beam is necessary.

\section{Hydrogen absorption in zirconium alloy}

Another example of application of the furnace is in situ observation of hydrogen absorption in metals, e.g., zirconium alloys used for nuclear fuel claddings, which is possible due to the high neutron attenuation coefficient of hydrogen. Figure 8 presents neutron images of zirconium alloy samples after $1 \mathrm{~min}, 20 \mathrm{~min}$, and $30 \mathrm{~min}$ of treatment in 5\% $\mathrm{H}_{2} 95 \%$ $\mathrm{Ar}$ at high temperature performed in our furnace. Images show $4.5 \mathrm{~mm}$ wide part of solid cylinders with a diameter 


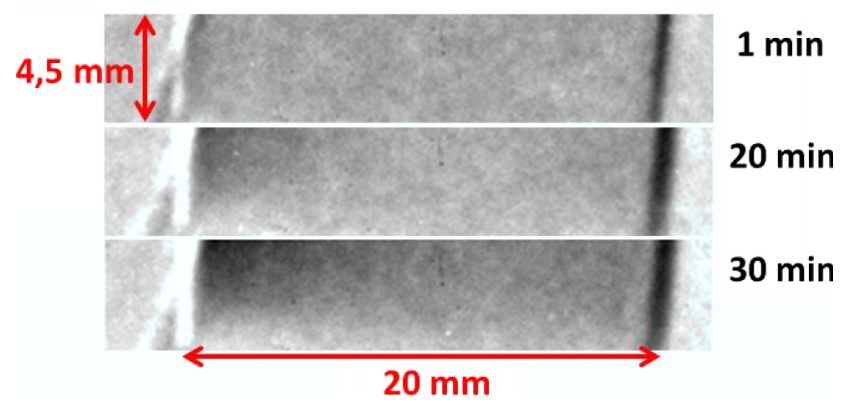

FIG. 8. In situ neutron imaging of hydrogen absorption in zirconium alloy measured at BOA beamline (PSI).

of $12 \mathrm{~mm}$ and a height of $20 \mathrm{~mm}$, which was limited by the field of view. The surface of the sample was oxidized before the experiment. One surface (on the left side in the images) was polished in order to remove the zirconia layer, so hydrogen could be transported into the material only through this surface. Images were normalized by division of each image by the initial state image. White and black stripes on the left and right sample surfaces, respectively, are artefacts caused by slight movement of the sample due to thermal expansion of the sample holder. Decrease of transmission with time on the left side of the sample indicates presence of hydrogen in the material. The hydrogen concentration can be full quantitatively determined if the dependence of the total neutron cross section on the hydrogen concentration is calibrated by means of samples with known concentration ${ }^{4}$ or for in situ measurements as described in Ref. 19. This test was performed at BOA beamline at PSI.

\section{B. Adaptation to further applications of the furnace}

The furnace has a very broad field of applications enabled by the possibility of using different conditions and its modifications. In this section examples of possible adaptations are described.

Each heater provides a power of $6 \mathrm{~kW}$, and only one is sufficient for many applications (Table II). To still ensure homogeneous heating and prevent temperature gradients to build up for bigger samples, a second (and a third and fourth) heater can be easily mounted in the chamber.

The position of the heaters can be adjusted in three dimensions and rotated along one axis. Flexible position of heaters in the chamber enables mounting of different or additional sample stages, stepper motors or a more complex sample environment, e.g., a stress rig. Also different sizes of the quartz tube for controlled atmosphere can be used for larger samples. Hence the geometry of set-ups in the furnace structure is highly flexible.

To observe three-dimensional structure e.g., of the cracks formed in the samples presented in Fig. 6, tomographic measurements ${ }^{38}$ are required. The sample holder in the furnace is equipped with a precise stepper motor, which can be used to perform neutron tomography measurements. Thus, using our furnace it is possible to perform simultaneously phase transition imaging (measuring Bragg edge patterns) combined with observation of $3 \mathrm{D}$ structure changes.
The furnace chamber can be closed with gas tight side plates. Closing the chamber enables introducing a specific atmosphere in the whole chamber. In this case, however, particular care is required to protect the heaters from exposure to reducing atmosphere.

Besides neutron imaging, the furnace can be used for neutron diffraction experiments. This is possible with standard furnaces available at many neutron facilities, but this sample environment can be used for in situ combined imaging and diffraction experiments as well as exploiting the outstanding features of fast heating, cooling and atmosphere changes. There are presently a few instruments at neutron facilities, e.g., ENGIN-X (ISIS), VULCAN (SNS), and HIPPO (LANSCE) (soon available also IMAT (ISIS)), where detectors for imaging and for diffraction can routinely be used simultaneously. Neutron diffraction experiments can be performed in controlled atmosphere, as on the outlet side of the quartz tube, two exchangeable flanges can be used, and the one presented in Figure 4(b) enables measurements in $90^{\circ}$ geometry. Using this setup significantly decreases accessible angular range to about 0.07 sr. For experiments, which do not require specific atmosphere, there is no need to use the quartz tube, which ensures good angular accessibility of the scattered neutrons to detectors over an angular range of about $1.5 \mathrm{sr}$.

\section{SUMMARY}

This new sample environment for in situ neutron imaging experiments requiring controlled atmosphere and elevated temperatures is presented. This is the first furnace allowing for in situ high spatial resolution neutron imaging. Its most important features are: minimized sample-detector distances of $25 \mathrm{~mm}$ (necessary for high spatial resolution), very small loss of neutron flux due to neutron beam attenuation by furnace elements $(<5 \%)$, very short time $(1-5 \mathrm{~min})$ required for achieving the required environmental conditions (temperature and atmosphere) and fast response to changing the conditions. The unique furnace design and the principle of operation enable a great flexibility for specific application and the key parameters of the furnace and potential applications were outlined. In addition specific examples of experiments were successfully performed with the presented sample environment underlining its remarkable functionality and performance.

\section{ACKNOWLEDGMENTS}

The authors would like to acknowledge John Jonson, Johnny Egtved Jørgensen, Jan Skov Andersen, Troels Feld for help in designing and building the furnace; Dr. Dirk Wallacher for his advises regarding furnace design and DanScatt for financial support. A portion of research performed at ORNL's Spallation Neutron Source was sponsored by the Scientific User Facilities Division, Office of Basic Energy Sciences, U.S. Department of Energy.

\footnotetext{
${ }^{1}$ See http://www asscientific com/products/furnaces/index.html for "AS Scientific Products: Products: Furnaces" (accessed 10 November 2014).

${ }^{2}$ N. Kardjilov, I. Manke, A. Hilger, M. Strobl, and J. Banhart, "Neutron imaging in materials science," Mater. Today 14(6), 248-256 (2011).
} 
${ }^{3}$ N. Kardjilov, A. Hilger, I. Manke, M. Strobl, M. Dawson, and J. Banhart, "New trends in neutron imaging," Nucl. Instrum. Methods Phys. Res., Sect. A 605(1-2), 13-15 (2009).

${ }^{4}$ S. H. Williams, A. Hilger, N. Kardjilov, I. Manke, M. Strobl, P. A. Douissard, T. Martin, H. Riesemeier, and J. Banhart, "Detection system for microimaging with neutrons," J. Instrum. 7(02), P02014 (2012).

${ }^{5}$ A. S. Tremsin, J. B. McPhate, J. V. Vallerga, O. H. W. Siegmund, W. B. Feller, E. Lehmann, A. Kaestner, P. Boillat, T. Panzner, and U. Filges, "Neutron radiography with sub-15 $\mu \mathrm{m}$ resolution through event centroiding," Nucl. Instrum. Methods Phys. Res., Sect. A 688, 32-40 (2012).

${ }^{6}$ M. Grosse, E. Lehmann, P. Vontobel, and M. Steinbrueck, "Quantitative determination of absorbed hydrogen in oxidised zircaloy by means of neutron radiography," Nucl. Instrum. Methods Phys. Res., Sect. A 566(2), 739-745 (2006).

${ }^{7}$ M. Grosse, M. Steinbrueck, E. Lehmann, and P. Vontobel, "Kinetics of hydrogen absorption and release in zirconium alloys during steam oxidation," Oxid. Met. 70(3-4), 149-162 (2008).

${ }^{8}$ M. Große, E. Lehmann, M. Steinbrück, G. Kühne, and J. Stuckert, "Influence of oxide layer morphology on hydrogen concentration in tin and niobium containing zirconium alloys after high temperature steam oxidation,” J. Nucl. Mater. 385(2), 339-345 (2009).

${ }^{9}$ R. Woracek, D. Penumadu, N. Kardjilov, A. Hilger, M. Boin, J. Banhart, and I. Manke, "3D mapping of crystallographic phase distribution using energy-selective neutron tomography," Adv. Mater. 26(24), 4069-4073 (2014).

${ }^{10}$ W. Kockelmann, G. Frei, E. H. Lehmann, P. Vontobel, and J. R. Santisteban, "Energy selective neutron transmission imaging at a pulsed source," Nucl. Instrum. Methods Phys. Res., Sect. A 578(2), 421-434 (2007).

${ }^{11}$ J. R. Santisteban, L. Edwards, M. E. Fizpatrick, A. Steuwer, and P. J. Withers, "Engineering applications of Bragg-edge neutron transmission," Appl. Phys. A: Mater. Sci. Process. 74, 1433-1436 (2002).

${ }^{12} \mathrm{~S}$. Vogel, "A Rietveld-approach for the analysis of neutron time-of-flight transmission data," Ph.D. thesis, Christian Albrechts Universitaet, 2000.

${ }^{13}$ A. S. Tremsin, J. B. McPhate, A. Steuwer, W. Kockelmann, A. M. Paradowska, J. F. Kelleher, J. V. Vallerga, O. H. W. Siegmund, and W. B. Feller, "High-resolution strain mapping through time-of-flight neutron transmission diffraction with a microchannel plate neutron counting detector," Strain 48(4), 296-305 (2012).

${ }^{14}$ M. Strobl, A. Hilger, M. Boin, N. Kardjilov, R. Wimpory, D. Clemens, M. Mühlbauer, B. Schillinger, T. Wilpert, C. Schulz, K. Rolfs, C. M. Davies, N. O'Dowd, P. Tiernan, and I. Manke, "Time-of-flight neutron imaging at a continuous source: Proof of principle using a scintillator CCD imaging detector," Nucl. Instrum. Methods Phys. Res., Sect. A 651(1), 149-155 (2011).

${ }^{15}$ M. Strobl, R. Woracek, N. Kardjilov, A. Hilger, R. Wimpory, A. Tremsin, T. Wilpert, C. Schulz, I. Manke, and D. Penumadu, "Time-of-flight neutron imaging for spatially resolved strain investigations based on Bragg edge transmission at a reactor source," Nucl. Instrum. Methods Phys. Res., Sect. A 680, 27-34 (2012).

${ }^{16}$ J. R. Santisteban, L. Edwards, and V. Stelmukh, "Characterization of textured materials by TOF transmission," Phys. B: Condens. Matter 385386, 636-638 (2006).

${ }^{17} \mathrm{~S}$. Vogel, J. C. Hanan, and L. Alamos, "Non-destructive in-situ real-time measurements of structural phase transitions," in Advances in X-ray Analysis (JCPDS-International Centre for Diffraction Data, 2001), Vol. 44.

${ }^{18}$ See http://www janis.com/Applications/NeutronScattering.aspx for "Cryostats for Neutron Scattering" (accessed 29 August 2015).

${ }^{19} \mathrm{P}$. Smeibidl, A. Tennant, H. Ehmler, and M. Bird, "Neutron scattering at highest magnetic fields at the Helmholtz Centre Berlin," J. Low Temp. Phys. 159(1-2), 402-405 (2010).
${ }^{20}$ A. Kahle, B. Winkler, B. Hennion, and P. Boutrouille, "High-temperature furnace for dynamic neutron radiography," Rev. Sci. Instrum. 74(8), 3717 (2003).

${ }^{21}$ J. Malzbender, R. W. Steinbrech, and L. Singheiser, "A review of advanced techniques for characterising SOFC behaviour," Fuel Cells 9(6), 785-793 (2009).

${ }^{22}$ A. B. Stambouli and E. Traversa, "Solid oxide fuel cells (SOFCs): A review of an environmentally clean and efficient source of energy," Renew. Sustain. Energy Rev. 6(5), 433-455 (2002).

${ }^{23}$ E. V. Tsipis and V. V. Kharton, "Electrode materials and reaction mechanisms in solid oxide fuel cells: A brief review. III. Recent trends and selected methodological aspects," J. Solid State Electrochem. 15(5), 1007-1040 (2011).

${ }^{24}$ M. Grosse, M. van den Berg, C. Goulet, E. Lehmann, and B. Schillinger, “Insitu neutron radiography investigations of hydrogen diffusion and absorption in zirconium alloys," Nucl. Instrum. Methods Phys. Res., Sect. A 651(1), 253-257 (2011).

${ }^{25}$ M. Grosse, M. van den Berg, C. Goulet, and A. Kaestner, "In-situ investigation of hydrogen diffusion in Zircaloy- 4 by means of neutron radiography," J. Phys.: Conf. Ser. 340(1), 012106 (2012).

${ }^{26} \mathrm{R}$. Toyoshima and H. Kondoh, "In-situ observations of catalytic surface reactions with soft x-rays under working conditions," J. Phys.: Condens. Matter 27(8), 083003 (2015).

${ }^{27} \mathrm{M}$. Argyle and C. Bartholomew, "Heterogeneous catalyst deactivation and regeneration: A review," Catalysts 5(1), 145-269 (2015).

${ }^{28}$ See http://www pcscontrols.com/ for "Leaders in Industrial Infrared Heaters, Systems and Control Solutions | Precision Control Systems, Inc. + Research, Inc." (accessed 10 November 2014).

${ }^{29}$ See http://www alumeco,dk/ for "Aluminium Solutions" (accessed 08 January 2015).

${ }^{30}$ M. Morgano, S. Peetermans, E. H. Lehmann, T. Panzner, and U. Filges, "Neutron imaging options at the BOA beamline at Paul Scherrer Institut," Nucl. Instrum. Methods Phys. Res., Sect. A 754, 46-56 (2014).

${ }^{31}$ S. Ramousse, M. Menon, K. Brodersen, J. Knudsen, U. Rahbek, and P. H. Larsen, "Manufacturing of anode-supported SOFC's: Processing parameters and their influence," ECS Trans. 7(1), 317-327 (2007).

${ }^{32}$ C. Grünzweig, G. Frei, E. Lehmann, G. Kühne, and C. David, "Highly absorbing gadolinium test device to characterize the performance of neutron imaging detector systems," Rev. Sci. Instrum. 78(5), 053708 (2007).

${ }^{33}$ A. S. Tremsin, J. B. McPhate, J. V. Vallerga, O. H. W. Siegmund, W. B. Feller, H. Z. Bilheux, J. J. Molaison, C. A. Tulk, L. Crow, R. G. Cooper, and D. Penumadu, "Transmission Bragg edge spectroscopy measurements at ORNL Spallation Neutron Source,” J. Phys.: Conf. Ser. 251, 012069 (2010).

${ }^{34}$ A. S. Tremsin, J. V. Vallerga, J. B. McPhate, and O. H. W. Siegmund, "Optimization of Timepix count rate capabilities for the applications with a periodic input signal,” J. Instrum. 9(05), C05026 (2014).

${ }^{35}$ M. G. Makowska, M. Strobl, E. M. Lauridsen, H. L. Frandsen, A. S. Tremsin, N. Kardjilov, I. Manke, J. F. Kelleher, and L. Theil Kuhn, "Effect of stress on $\mathrm{NiO}$ reduction in solid oxide fuel cells: A new application of energy-resolved neutron imaging," J. Appl. Crystallogr. 48, 401-408 (2015).

${ }^{36}$ M. G. Makowska, M. Strobl, E. M. Lauridsen, H. L. Frandsen, A. S. Tremsin, T. Shinohara, and L. Theil Kuhn, "Phase transition mapping by means of neutron imaging in SOFC anode supports during reduction under applied stress," ECS Trans. 68(1), 1103-1114 (2015).

${ }^{37}$ M. G. Makowska, L. Theil Kuhn, E. M. Lauridsen, H. L. Frandsen, S. Kabra, W. Kockelmann, A. S. Tremsin, and M. Strobl, "In-situ time-of-flight neutron imaging studies of NiO-YSZ reduction under influence of stress" (unpublished).

${ }^{38}$ M. Strobl, I. Manke, N. Kardjilov, A. Hilger, M. Dawson, and J. Banhart, "Advances in neutron radiography and tomography," J. Phys. D: Appl. Phys. 42(24), 243001 (2009). 